\title{
Optical Lenses moulded from Plastic Material
}

$\mathrm{A}^{\mathrm{N}}$ interesting exhibition of optical lenses moulded from plastic materials was held on February 9 at the Waldorf Hotel, London, under the auspices of the Combined Optical Industries, Ltd. Those responsible for the production of the material and for the process of moulding it are Mr. A. Kingston, the inventor, and Mr. Peter Koch de Gooreynd, chairman of the company, who has been associated with the development of the process.

It is claimed that this invention, which is British in origin and development, offers an opportunity for the increase of an industry in which Great Britain has hitherto taken a comparatively small share. The optical medium is produced from various plastic and transparent materials of a resinous character. It is originally prepared in sheets, which are guillotined into strips and then into small squares. These are subjected to a special treatment in which compression and the maintenance of temperatures of varying degrees play an essential part. The refracting surfaces are produced by moulding, and lenses polished and ready for mounting are delivered from specially designed machines. The long and difficult process of grinding at present necessary in the manufacture of optical systems is thus avoided, and it is evident that the cost of the production of the essential parts of optical instruments can be very greatly reduced.

The lenses shown at the exhibition were made of a particular form of the plastic material known by the trade name of 'Perspex'. It is a substance of high transparency, very light, being about half the density of glass, and practically unbreakable. It is possible to throw one of the lenses with great force on to a marble table without damaging the surfaces so far as can be seen by eye. It appears that the material can recover from a considerable degree of strain without apparent permanent set.

The refractive index of the material has been determined by the method of apparent depth and was found to be approximately the same as that of crown glass. It is extremely transparent in the ultraviolet region extending to $2700 \mathrm{~A}$. but is more absorbent in the infra-red.

These properties of the material suffice to show that it has the right to be regarded as a valuable optical medium, which may well exercise a revolutionary influence in the optical industry. Cameras, spectacles, range-finders and similar apparatus can be produced more quickly and cheaply and in a more robust form in this material than in glass. A striking exhibit was a photograph enlarged about twenty times showing excellent detail. Small opera glasses exhibited very little colour effect, although it is true that the magnification was not more than three diameters.

Certain questions naturally arise as to the possibility of the development for the manufacture of accurate scientific apparatus, where it is essential to eliminate the effects of aberrations. It appears that a number of different kinds of plastic materials is available, and, if they can be produced with the right dispersive powers and refractive indices, there is obviously a great future for the material in the field of research.

It appears that surfaces can be silvered. Can they be produced optically flat, and is the medium so optically perfect that it can form a Lummer plate? We do not know if information on such points is available yet, but enough was shown at the exhibition to supply convincing proof that, in the wide and extending field where optical instruments come into contact with modern life, this medium will play an important role.

\section{The British Electrical and Allied Industries Research Association}

T HE sixteenth annual report, covering the period from October 1935 to September 1936, of the British Electrical and Allied Industries Research Association, now usually called E.R.A., has been published. It shows that its research work is rapidly increasing in magnitude and importance. When the formation of research associations in Great Britain was first considered some twenty years ago, their value to industry was considered highly problematical by many. This distrust is now completely dispelled. It can be proved that their work has resulted in the saving of millions of pounds every year to the consumers. In the electrical industry alone it has resulted in a great increase in the continuity of the supply and the length of life of the cables and the efficiency of the lamps.

Knowledge cannot be gained without expense. The funds contributed by the manufacturers and the equal contributions from the Government are converted into 'knowledge stock' which the chairman of the council of E.R.A. calls a priceless national asset which repays the investor by ever increasing dividends of prosperity and progress. There are 450 voluntary workers, some of them well-known experts, serving on the various committees of E.R.A. The electrical industry is one of the best organized in the country and now fully recognizes the commercial value of research. Within its present field there are many problems still to be solved by E.R.A. When solutions are obtained, some of them will doubtless lead to the active development of profitable branches of the industry.

A very happy state of affairs is disclosed in the report by the way this Association co-operates with the leading engineering institutions, with numerous international committees, with the Electricity Commission, with the G.P.O., the B.B.C. and the Radio Manufacturers' Association. Its financial position is very sound. It has built up its laboratory at a cost of $£ 26,000$ out of its own reserve fund. Out of 
a total income of $\mathfrak{£} 68,000$ last year, the Department of Scientific and Industrial Research contributed $£ 19,000$.

Of individual researches, we may mention the research on the electric strength of thin dielectrics and varnish films. The electric strength of mica has been found to be constant up to $300^{\circ} \mathrm{C}$. This value agrees with certain calculations based on recent theories. The oscillographic studies of the current and voltages which occur during a breakdown have led to valuable practical results. A research is proceeding on the deleterious effects of ionization products and coronæ (brush discharges). Two papers were presented on behalf of E.R.A. to the British Association, by Dr. S. Whitehead and Prof. W. M. Thornton respectively. The latter is also revising the tables for spark-gap calibration.

Important tests were carried out with the co-operation of the Central Electricity Board, on the Portsmouth-Reading line, on the interference produced by high harmonics in neighbouring circuits, and a report will also be issued. A number of reports on interference were presented to the Commission Mixte Internationale, and some of the conclusions put forward were incorporated in the final recommendations. The issue of a report by the Institution of Electrical Engineers on electrical interference with broadcasting brought the large-scale co-operative researches co-ordinated by E.R.A. to a close. They have been superseded by a series of investigations which aim at (1) obtaining accurate data and limits for standard specifications and (2) compiling reports upon specific matters of interest to manufacturers of electrical plant. In railway engineering research, it has been found that cadmium-copper wire shows considerably less wear than pure copper as a trolley wire material ; the small quantity of cadmium present only reduces the conductivity of the wire by a small amount. Its freedom from stretching makes this alloy of copper very suitable for use as a trolley wire.

The report is published by E.R.A., 15 Savoy Street, W.C.2.

\section{International Fisheries Research*}

$\mathrm{T}$ HE twenty-ninth reunion of the Conseil Permanent International pour l'Exploration de la Mer was held in Copenhagen in May 1936 under the presidency of Mr. Henry B. Maurice. The present position being unchanged, all the States now participating will continue for another five years as from July 22 of last year. Latvia is now desirous of becoming a full member.

Among the many subjects involved was the position of the various countries as regards size limits and mesh regulations (Point 7 of the agenda), the president having circulated a memorandum previously prepared by himself summarizing, so far as was possible, the present position with regard to mesh regulations and size limits.

Three special scientific meetings were held during the Council meeting of 1936 , the first to discuss the physiological problems of interest to the marine biologist in his studies of the most important species of fish, the second to compare stocks of fish in the several areas in respect of age composition, the third on the measurement of submarine light and its relationship to biological phenomena. The programmes and reports of the different area committees are included in Part 1 of the Rapports et Procès-verbaux.

Part 2 includes the Administration Report, which was passed without amendment. A large part of this has to do with the herring. A special meeting of herring experts was held at Lowestoft on October 16-17, 1935. Besides the report with recommendations, there are papers on the herring from the Skagerak, Kattegat and Baltic, Fladen Ground, Western European waters, the Southern Bight, the southern part of the Transition Area, Faroes, Iceland and Greenland, and from Scotland, also others on race questions, populations and larvæ. M. le Gall's paper on the present state of knowledge

- Conseil Permanent International pour l'Exploration de la Mer. Rapports et Procès-verbaux des Réunions. Vol. C. lère partie : Procès-verbaux (Mai 1936). Pp. 62. 3.00 kr. 2ème partie : Rapport administratif (1935-36). 3eme partie: Appendices. Pp. $111+25$ $4.00 \mathrm{kr}$. (Copenhague : Andr. Fred. Høst et flls.) concerning the origin and distribution of herring populations in western European waters was specially discussed.

The following recommendations were made. Any group of herring spawning in a given area at a given season from year to year should be defined as the natural 'Biological Group', and morphological characters should be used as a practical aid in the identification of these biological groups outside the area and season of spawning. Work on biological groups and other local and seasonal population should be continued. Vertebral counts of selected material should be continued, additional characters such as the number of keel scales being also studied when necessary. A co-operative study should be undertaken on the practicability of utilizing a count of separate portions of the vertebral series in such a way as to draw distinctions between morphologically distinguishable groups with a minimum of labour and material. Spawning times should be defined by stating the actual month, and in the northern area group, characters of the autumn and spring spawning populations on the north-west coast of Iceland should be investigated and compared. All countries working in one way or another in the waters of the Faroes, Iceland and Greenland should arrange for material of herring to be collected for age determinations and distribution of larval stages; fishing experiments should be carried out in the open sea between Norway, Faroe Isles and eastern Iceland to collect material in order to get information as to the exchange of population between different parts of this region; and the collecting work concerning age composition, population-characters, exact determination of maturity and distribution of larvæ should be carried out in all important areas systematically and continuously for a period of years. Samples of spawning herring from the Viking Bank should be collected and investigated as opportunity occurs; samples from western Greenland and from Labrador should be collected with the view of comparing the population characters, age composition, spawning time and 